\title{
A Retórica da Metáfora dos Modelos na Teoria do Direito $^{1}$
}

\author{
The Rhetoric of Models' Metaphor in Legal Theory
}

Pedro Parini

Universidade Federal da Paraíba, João Pessoa - PB, Brasil

Resumo: Parte-se de uma perspectiva retórica com o objetivo de indagar acerca da pertinência de se estabelecer, mais do que simples cânones interpretativos e retóricos, paradigmas epistemológicos hermenêuticos e/ou argumentativos e seus correspondentes modelos teóricos que legitimem o trabalho de produção do direito, em especial no que se costuma chamar de "aplicação normativa". Pretende-se avaliar se a manipulação do direito está atrelada a uma epistemologia ou a uma retórica, ou ainda a uma possível, mas improvável, epistemologia retórica da metáfora.

Palavras-chave: Retórica. Metáfora. Modelo.

\begin{abstract}
A rhetorical view is here assumed with the purpose of inquiring about the pertinence of establishing - more than simple interpretative and rhetorical canons - epistemological and/or argumentative paradigms and their correlative theory models that legitimate the making of the law, especially concerning what is called "normative application". We intend to evaluate in what degree is the manipulation of law dependent on an epistemology or on a kind of rhetoric, or still on a possible but maybe improbable rhetorical epistemology of metaphor.
\end{abstract}

Keywords: Rhetoric. Metaphor. Model.

\section{Introdução}

O presente texto objetiva indagar sobre a pertinência de se estabelecer paradigmas epistemológicos hermenêuticos e/ou argumentativos que legitimem o trabalho de produção do direito. Pretende-se avaliar em que medida o problema metodológico de manipulação da noção de direi-

\footnotetext{
${ }^{1}$ Recebido em: 10/07/2013

Revisado em: 1\%/10/2013

Aprovado em: 10/10/2013
} 
to está atrelado a uma epistemologia ou a uma retórica, ou ainda a uma possível, mas improvável, epistemologia retórica própria da "retórica analítica". Nesse sentido, propõe-se o esboço de uma crítica à concepção cientificista da teoria do direito que parece não desistir da ideia de que a legitimação da atividade jurídica de aplicação normativa depende do estatuto epistemológico das teorias que, além de descreverem-na, prescrevem regras para o seu correto funcionamento. Essa crítica não se aplica apenas às perspectivas positivistas da teoria jurídica, mas também às concepções pós-positivistas que, mesmo ao procurarem superar as limitações metodológicas do positivismo lógico da primeira metade do século XX, ainda consideram pertinente a noção de epistemologia na teoria do direito, ainda que a partir de novos paradigmas, como o hermenêutico e o argumentativo.

A tradicional concepção epistemológica do direito encara, de um lado, as teorias como modelos descritivos de uma realidade que é ou que existe, e, de outro lado, como modelos prescritivos que procuram impor ao jurista prático uma metodologia de abordagem dos problemas jurídicos a partir de uma realidade que deve ser. Retoricamente, a elaboração de teorias desse tipo pode ser compreendida a partir de uma concepção metafórica da estrutura dos modelos teóricos e de seu papel como teoria, ora figurando como expedientes meramente descritivos $d a$ realidade, ora como ou constitutivos de uma realidade (contingente dentre outras possíveis) do fenômeno jurídico.

Parte-se do pressuposto de que esses modelos pouco têm de descritivos, pois as linguagens que as teorias estabelecem estão mais para um fenômeno de criação de uma realidade autônoma do que uma explicação de algo objetivo que existe em si. Nesse sentido, uma perspectiva filosófica que parte da teoria retórica, portanto, entende que os modelos teóricos se assemelham a metáforas que dependem em menor medida do poder explicativo da teoria do que da capacidade de redescrição poética decorrente do que se chama de "imaginação científica" (RICOEUR, 2005, p. 366). Assim como a criação do direito deveria ser guiada por regras tidas como racionais, a aplicação, da mesma forma, deveria seguir um método adequado para que seja considerada legítima. No âmbito do pensamento jurídico moderno, pois, tudo que não é racional, ou que não se justifica 
racionalmente, é tratado como arbitrário. E, dessa exigência de racionalidade, origina-se a necessidade de se estabelecer teoricamente postulados científicos da produção jurídica que a satisfaçam. Em razão disso é que a noção de direito passa a ser identificada com o conceito de norma, ou de ordenamento jurídico, ou ainda de fato juridicamente determinado. A noção de estrutura lógica da norma jurídica, ou as características sistêmicas de unidade, coerência e completude, inerentes à ideia de ordenamento, são exemplos típicos de construções teóricas de modelos ou arquétipos desenvolvidos no contexto de afirmação e determinação da epistemologia jurídica positivista. Já as noções de argumentação racional e de interpretação são empregadas como modelos teóricos para uma epistemologia pós-positivista. Cada uma dessas noções representaria um modelo teórico determinado para a aplicação do direito.

Pretende-se, portanto, compreender em que medida a produção desses modelos teóricos do direito se assemelha ao processo criativo e interacional de produção de metáforas. Longe de serem literais, os enunciados teóricos da "ciência" jurídica revelam mais a capacidade criativa e intuitiva do teórico do que propriamente uma relação de correspondência com as diversas realidades do direito. Além disso, o arsenal linguístico das teorias jurídicas parece empregar metaforicamente tanto os termos lógicos de um vocabulário instrumental formal, quanto os termos observacionais de um vocabulário de referência à realidade observável, resultando em uma retórica que produz um vocabulário teórico constitutivo de entidades, propriedades e relações que já não são mais diretamente observáveis na realidade efetivada.

\section{Retórica, Hermenêutica e Epistemologia na Teoria do Direito}

O primeiro ponto de partida para a análise crítica aqui proposta são as discussões relativamente recentes sobre teoria do direito realizadas por Paul Ricoeur. Mesmo não sendo o direito o seu principal objeto de investigação - pois antes de se interessar propriamente por problemas da teoria jurídica, são questões da psicologia, da teologia, da história, da hermenêutica e da teoria da linguagem os principais temas de suas obras - o 
olhar crítico e, de certa forma, externo sobre o que fazem os juristas parece relevante.

Certamente a crítica externa de Ricoeur representa um movimento de retorno às origens dos fundamentos teóricos da própria tradição da teoria hermenêutica do direito, pois as bases epistemológicas das teorias da interpretação jurídica estão fora da teoria do direito tomada em sentido estrito. Ricoeur, pois, é um representante dessa corrente filosófico-hermenêutica que procura entender como os juristas absorveram uma tradição não jurídica e de que forma aplicaram-na aos problemas propriamente jurídicos. Além disso, a importância de Ricoeur para esse trabalho está no fato de que representa uma aproximação entre duas tradições bem distintas, a hermenêutica e a retórica. Desde a nova hermenêutica de Schleiermacher e Dilthey até a hermenêutica filosófica de Heidegger e Gadamer que a noção de interpretação está associada ao problema epistemológico e ontológico da verdade. Ricoeur não é infiel a essa tradição, se preocupa com o tema da verdade, mas, em certa medida, trilha seu próprio caminho. Ou melhor, Ricoeur é responsável por apontar os vários pontos de convergência entre uma atitude retórica (limitada ao âmbito da verossimilhança) e uma preocupação hermenêutica na filosofia (ainda envolvida com o problema da verdade). De acordo com seu ponto de vista, uma teoria da metáfora, tipicamente retórica, por exemplo, torna-se essencial à tarefa de reconstrução de significados da hermenêutica. Superfície e profundidade, mito e verdade, imagem e realidade seriam assim contemporaneamente problemas retóricos e hermenêuticos.

A hermenêutica proposta por Ricoeur inclui, além de elementos da teoria psicológica das imagens e dos sentimentos, uma teoria semântica das metáforas. E isso significa precisamente que há para ele um valor cognitivo na linguagem figurada relativo à capacidade que as metáforas têm de transmitir informações que não podem ser traduzidas em uma linguagem literal, mas que, ao mesmo tempo, garantem algum insight sobre a realidade (RICOEUR, 1978, p. 151). A noção de verdade metafórica se traduz na intenção realista ligada ao poder de redescrição da linguagem poética, ou seja, na pretensão do enunciado metafórico de atingir a realidade. (RICOEUR, 2005, p. 376) 
O segundo ponto de vista para a presente crítica a esse desejo por epistemologia é o da retórica analítica do direito (BALLWEG, 1982; 1987; 1991a; 1991b). Isto é, parte-se de uma perspectiva ao mesmo tempo retórica e reflexiva do caráter intrinsecamente retórico (e figurado) da linguagem jurídica no que se chama de retórica material do direito e do discurso jurídico em um maior nível de abstração da própria teoria dogmática, o que se chamou de retórica prática ou estratégica (ADEODATO, 2009 , p. 37). A retórica analítica pode ser entendida como uma espécie de filosofia retórica ou retórica teórica com alto grau de abstração que pretende se distanciar da retórica material, imunizando-se contra as armadilhas da linguagem natural - mas ao mesmo tempo reconhecendo a impossibilidade de neutralizá-las por completo - e de todo seu caráter metafórico. Mas, ao passo em que procura transcender esse nível das relações humanas comunicacionais, está ciente de sua própria condição retórica. Ou seja, desde o início, o filósofo retórico tem consciência de que todo seu discurso teórico não passa de mais um modelo ou imagem complexa repleta de metáforas sobre aquilo que se concebe como o mundo real. Todo trabalho de retórica analítica ao mesmo tempo em que se pretende científico, puramente descritivo, axiologicamente neutro e dissociado das vicissitudes e contingências da simples empiria, reconhece que não faz nada mais do que elaborar mais um conjunto de narrativas, mais uma retórica que pode vir a ser objeto de uma nova retórica analítica, mais abstrata, mais reflexiva, mais teórica e, ainda assim, retórica. Se não fosse o caráter circular decorrente da consciência de sua retoricidade, a retórica analítica seria, na verdade, uma traição à própria retórica. Por essas razões, o teórico retórico do direito não fala em teoria geral do direito, mas em retórica teórica do direito, rica em generalizações. No entanto, tradicionalmente, a atitude teórica é bem diversa. É preciso lembrar: sem postulados, enunciados ou proposições universais, não se pode fazer epistemologia, e sem epistemologia, não se pode falar em ciência do direito; direito sem ciência que o justifique epistemologicamente, indica ausência de racionalidade; e, sem racionalidade, só restaria para o jurista casuísmo e arbitrariedade. Dessa forma, a dogmática jurídica precisaria estabelecer pelo menos alguns postulados mínimos que garantissem uma base epistemológica para a produção racional do direito moderno. Esses postula- 
dos são em geral resumidos a dois constrangimentos: a inegabilidade dos pontos de partida e a obrigatoriedade de decidir ${ }^{2}$.

Mas nada impede que, analiticamente, esses dois postulados possam vir a ser ampliados em novas exigências, como, em especial, o constrangimento de interpretar e de argumentar dogmaticamente (ADEODATO, 2009, p. 216). Claro, pode ser arriscado pressupor que as exigências de interpretação e argumentação já estejam contidas no postulado da inegabilidade dos pontos de partida. Na verdade, o que se percebe no desenvolvimento histórico da teoria jurídica é que esses dois momentos da produção normativa passam a ter relevância somente com o desenvolvimento de teorias hermenêuticas e argumentativas do direito, sobretudo no que se convencionou chamar de "guinada interpretativa" (JUST, 2006) do direito. Procura-se avaliar retórica e criticamente algumas questões sobre o papel metodológico desempenhado por essas novas teorias jurídicas pós-positivistas que fazem parte da, assim chamada, jurisprudência hermenêutica e que partem de um novo modelo de racionalidade para a produção do direito colocando a interpretação normativa e a argumentação jurídica no centro da própria atividade jurisdicional.

Revoluções científicas que acarretam mudanças de paradigmas como do positivismo jurídico para o pós-positivismo - podem ser entendidas como revoluções metafóricas. E novas explicações teóricas podem ser vistas como redescrições metafóricas de um mesmo fenômeno, posto que a metáfora nos permite "ver" o fenômeno de maneiras diferentes, investindo-o de diferentes significados e compreendendo-o circunstancialmente (ARBIB; HESSE, 2008, p. 156). Toda nova metodologia jurídica traz consigo novas exigências e novos paradigmas formais e materiais para a confecção de um modelo que se pretende mais autêntico em relação a uma ontologia do direito. O paradigma hermenêutico concebe a noção de direito como uma prática essencialmente interpretativa e que, para tanto, depende de um modelo que leve em consideração esse seu caráter fundamentalmente hermenêutico. A discussão que começa na filosofia e chega à teoria do direito vai além dos limites de uma tecnologia de so-

2 Sobre a estrutura e a função do pensar dogmático no direito, ver Viehweg (1991, p. $101,118,146)$. 
lução de conflitos sociais, passando por uma avaliação das bases epistemológicas da ciência do direito e chegando a uma ontologia na busca da própria essência hermenêutica do direito.

A interpretação normativa como arte ou técnica foi já objeto da reflexão teórica dos juristas renascentistas. $\mathrm{Na}$ verdade, o problema da interpretação estava intrinsecamente ligado ao problema da determinação do direito (a se aplicar em situações determinadas). A interpretação representava algo essencial ao próprio processo - que hoje, a partir de nossos modelos, chamar-se-ia - de "normatização" do direito, especialmente no direito comum pré-moderno em que a lei não figurava ainda como principal "fonte" do direito (DEL FRATE, 2000, p. 7), outro modelo importante para a visão do jurista moderno. Com o advento da Modernidade e do surgimento de novos paradigmas científicos, o problema do conhecimento, ou dos fundamentos teóricos do conhecimento, passa a ser algo central para a filosofia. Mas é apenas no século XIX que a hermenêutica passa a ter relevância teórica para a discussão epistemológica. Os filósofos passam a procurar na hermenêutica as bases epistemológicas para as ciências históricas (RICOEUR, 1977, p. 24), dentre elas o direito.

Mas o problema filosófico mais recente, mesmo sem dela se destacar, procura ultrapassar os limites da epistemologia, representando um retorno mesmo à ontologia. Existe uma tendência entre os teóricos da hermenêutica de universalização do ponto de vista interpretativo no âmbito da produção de conhecimento. O primeiro passo significativo nessa direção corresponde à passagem das várias hermenêuticas regionais a uma hermenêutica geral. Isto é, ocorre um movimento de superação de uma concepção tecnicista da interpretação, em que hermenêutica deixa de ser um mero conjunto de cânones interpretativos que se diferenciam em cada âmbito de aplicação e passa a constituir um verdadeiro paradigma para as ciências do espírito como um todo. $\mathrm{O}$ segundo passo consiste em superar essa preocupação puramente epistemológica de conferir status científico a essas formas de saber e apresentar o compreender como uma forma de ser e não somente de conhecer. (RICOEUR, 1977, p. 18, 29, 33)

A noção moderna de ciência, inclusive de "ciência jurídica", passa obrigatoriamente pela necessidade de objetivação do conhecimento. 
O método é uma garantia de objetividade ${ }^{3}$. Na tentativa de se assegurar ao direito algum status epistemológico, qualquer incursão no âmbito da metodologia das ciências naturais é prematuramente percebida como um passo em direção ao fracasso. Um modelo autêntico de racionalidade só poderia ser alcançado em uma ontologia que lhe seja própria, isto é, que corresponda a sua forma de ser ou de existir.

Obviamente direito não é um fenômeno natural que pode ser captado no mundo de maneira absolutamente objetiva. Mas tampouco é um elemento artificial cuja existência é completamente contingente. Isto é, o direito como objeto do conhecimento é algo que não pode ser apreendido racionalmente em sentido estrito (isto é, no sentido de poder ser submetido a postulados inequívocos), ao mesmo tempo em que é possível desenvolver uma metodologia capaz de objetivá-lo, garantindo assim a sua parcial comunicabilidade.

A noção de direito como fenômeno social historicamente determinado, portanto, é reconhecida como prática interpretativa que precisa se submeter a uma metodologia capaz de lidar com esse seu caráter propriamente hermenêutico, mas que envolve também necessariamente processos argumentativos. A questão é que, epistemologicamente, o máximo que se pode obter de uma ciência jurídica que estabelece padrões ou modelos para a legitimação teórica dessas práticas é uma espécie de "crença". Uma crença que se coloca entre "conhecimento" mesmo e mera "ilusão". Crença indica "ponto de vista" que se relaciona com um processo em certa medida "divinatório" de antecipação de resultados que, por sua vez, se localiza entre o uso da "razão" e o da "imaginação". Os modelos teóricos para a aplicação do direito - sejam argumentativos ou hermenêuticos - seriam, pois, produzidos por um processo misto (racional e imagético) que se aproxima do processo de produção de metáforas, como se verá mais adiante.

\footnotetext{
3 O racionalismo moderno cartesiano encara as discrepâncias entre as inúmeras opiniões sobre a realidade como simplesmente o emprego equivocado da razão. "A diversidade das nossas opiniões não provém do fato de uns serem mais racionais do que outros, mas tão-somente em razão de conduzirmos o nosso pensamento por diferentes caminhos e não considerarmos as mesmas coisas. Pois não basta ter o espírito bom: o essencial é aplicá-lo bem." (DESCARTES, 2004, p. 21)
} 


\section{O Caráter Discursivo e Interpretativo da Prática Jurídica: aproximação e distanciamento entre 0 modelo argumentativo e o modelo interpretativo do direito}

Recentemente, nas últimas quatro décadas, a teoria do direito, como mencionado, tem sido fortemente influenciada pelos novos paradigmas interpretativos da hermenêutica fillosófica e da argumentação racional. De certa forma, essa mudança de rumo da jurisprudência tem como pano de fundo o debate proposto pelas teorias chamadas pós-positivistas do direito. O formalismo e o estruturalismo adotados como modelo teórico das correntes positivistas pareceram insuficientes aos olhos dos juristas pós-positivistas e, assim, questões de conteúdo do direito passaram a ser novamente levadas a sério a partir de novos modelos ou paradigmas formais.

Ao lado dessa discussão material, os juristas pós-positivistas colocam também o problema metodológico da indeterminação do direito, relativa ao momento específico de aplicação normativa. É justamente nesse contexto que ganham relevância uma teoria jurídica da argumentação e da interpretação assumindo o papel de novos modelos teóricos de legitimação racional da tarefa de decidir, ora preocupadas em estabelecer postulados formais de argumentação ou interpretação, ora se imiscuindo em tentativas de definições de conteúdo.

A questão é que, mesmo fazendo parte de um movimento crítico relativamente uniforme ao positivismo jurídico, as teorias pós-positivistas terminam enveredando por caminhos distintos, até mesmo antagônicos. Segundo Ricoeur, no âmbito da teoria do direito, argumentação e interpretação seriam supostamente operações rivais, apesar de tratadas nesse contexto de um debate unificado. Uma divergência desse tipo, porém, põe em xeque a coerência epistemológica do que ele chama de "debate judiciário” (RICOEUR, 2008, p. 153). Em sentido amplo, a interpretação normativa identifica-se com a noção de aplicação do direito, isto é, aplicação da norma ao caso concreto. Dado que uma tarefa desse tipo se caracteriza pela agonística típica do debate judiciário, a noção de argumentação parece ser fundamental para o momento da aplicação do direito e, portanto, da 
interpretação normativa, já que interpretação e aplicação não estão dissociadas no âmbito jurídico.

Ao colocar lado a lado interpretação e argumentação, pelo menos dois modelos distintos de construção teórica são possíveis. Em primeiro lugar, uma concepção antinômica da polaridade entre interpretação e argumentação, ou seja, a não identificação e consequentemente a exclusão mútua de ambas as perspectivas teóricas. Em segundo lugar, uma versão dialética dessa polaridade, em que a oposição de ideias se presta a um fim que as transcende.

Em geral, o que se pode constatar, segundo Ricoeur, é que o tratamento do tema, na teoria do direito, parte normalmente da concepção não dialética dessa polaridade, pois os autores que tratam da interpretação do direito, ou do problema hermenêutico em sentido estrito, não se preocupam em confrontar o tema com o problema argumentativo. A mesma coisa parece acontecer entre os teóricos da argumentação jurídica, não sendo a interpretação reconhecida como componente original do discurso jurídico. Segundo Ricoeur, essa desvinculação entre os dois âmbitos (o interpretativo e o argumentativo) representa um indício de deficiência ou insuficiência teórica de ambos os lados. Uma abordagem suficientemente adequada do debate judiciário partiria necessariamente da visão dialética do problema, isto é, das relações não necessariamente excludentes entre interpretação e argumentação. (RICOEUR, 2008, p. 154)

Para realizar uma tarefa desse tipo, Ricoeur parte da analogia entre o binômio interpretação/argumentação na esfera jurídica e a tradicional distinção epistemológico-hermenêutica entre compreensão/explicação no campo da teoria do texto, da teoria da ação e da teoria da história. Como se sabe, a hermenêutica jurídica de Ronald Dworkin, por exemplo, tem como ponto de partida imediato o conceito teórico dos "casos difíceis" (hard cases), que por sua vez são um reflexo direto da atividade prática dos juízes diante de casos concretos ${ }^{4}$. Uma teoria interpretativa desse

\footnotetext{
4 Para Gustavo Just (2006), além de um “interpretativismo cultural geral” que acompanha a Pós-modernidade filosófica, o caráter interpretativo da prática jurídica, ou melhor, a tomada de consciência desse caráter interpretativo da experiência jurídica é um elemento fundamental para o desenvolvimento do interpretativismo na teoria do direito.
} 
tipo surge em razão da oposição direta ao positivismo jurídico e aos seus pressupostos (a necessidade de se considerar a intenção do legislador, a univocidade das disposições normativas e a discricionariedade do decisor diante de uma situação de ausência de critérios normativos para a solução do problema). Os argumentos contrários a esses axiomas desenvolvidos pelas teorias positivistas do direito são inúmeros e se coadunam na generalidade do problema hermenêutico da indeterminação de sentido textual e da independência do texto em relação a seu autor.

Não que os positivistas não tivessem consciência da indeterminação da linguagem jurídica e, por conseguinte, do texto normativo. Veja-se como exemplo a tese da textura aberta que Herbert Hart (2002, p. 150) toma emprestado ${ }^{5}$ da filosofia da linguagem de Friedrich Waismann ${ }^{6}$ para caracterizar a linguagem do direito, como derivada da linguagem natural, como relativamente indeterminada em relação à experiência. Para Waismann, toda linguagem empírica é limitada no seu poder de descrição, pois todo enunciado empírico escapa a uma verificação absolutamente conclusiva. Nesse sentido, tanto Hart quanto Waismann estão de acordo no que diz respeito à incerteza que decorre de situações ainda não vividas e tampouco previstas. Não é possível antever todas as circunstâncias futuras em que o conceito será submetido a uma verificação de seu valor de verdade (BIX, 2003, p. 11). Ou seja, os enunciados que descrevem o fenômeno real nunca alcançam uma definição satisfatória do objeto descrito.

Não se pode esquecer a obra paradigmática da teoria juspositivista, a Teoria pura do direito de Hans Kelsen, sobretudo para a tradição latino-americana. O famoso e lacônico capítulo oitavo da obra, que só aparece em sua segunda e tardia edição, sobre a interpretação do direito, chega a uma conclusão semelhante sobre a indeterminação da linguagem das normas e, portanto, da falta de segurança epistemológica a respeito do

5 Para uma polêmica entre o conceito de textura aberta da linguagem entre Hart e Waismann veja-se a análise de Brian Bix (2003, p. 7-35).

6 Waismann não tem, diferentemente em relação a Hart, uma preocupação direta com o direito. A adaptação da teoria depende da liberdade com que Hart manipula o conceito. Nada obstante, é possível encontrar em Waismann uma análise filosófico-linguística da estrutura e da função do conceito de regra partindo da descrição de um exemplo prático tirado das regras do jogo de xadrez. (WAISMANN, 1985, p. 191-219) 
caráter cognitivo do ato de decisão judicial ${ }^{7}$. Segundo Kelsen, não há um método qualquer de direito positivo que seja capaz de determinar um caminho correto para a interpretação das normas ${ }^{8}$, pois "[...] não é da ciência positiva normatizar a semântica da linguagem natural" (CASTRO JR., 2009, p. 76). A “[...] relativa indeterminação do ato de aplicação do direito [...]" é uma decorrência direta da pluralidade de significações da expressão verbal da norma, cujo sentido não é unívoco. Além dos casos de indeterminação intencional, quando o legislador (ou autor da norma) deixa conscientemente uma margem de livre apreciação para o aplicador da norma, há os casos em que o órgão aplicador se vê diante várias significações possíveis para um mesmo texto normativo. (KELSEN, 1987, p. 364-365)

Já entre os pós-positivistas, no caso da teoria hermenêutica do direito de Ronald Dworkin e da teoria da argumentação jurídica de Robert Alexy, se comparadas às teorias retóricas, o que se tem é uma situação de maior otimismo em relação às dificuldades do jurista diante das situações de indeterminação do direito. Se por um lado a própria noção de direito, ou a sua linguagem, ou ainda o discurso jurídico, são indeterminados em virtude de uma infinidade de razões, ainda assim deve subsistir no jurista teórico um ideal de racionalidade que, se não está na analiticidade do método, nem na linearidade do conhecimento, nem tampouco na dedutibilidade da inferência lógica do processo de subsunção normativa, deve ser buscado em outras esferas, como, por exemplo, na lógica informal do discurso, na razão prática da moral, ou mesmo na teoria literária que deverão atuar como modelos para sua construção teórica.

\footnotetext{
7 É curioso que o ceticismo do realismo interpretativo tenha se identificado, mesmo que embrionariamente, com a tese sobre a interpretação da Teoria pura do direito. A teoria realista da interpretação jurídica parte simplesmente da observação da prática interpretativa e do fato de que os textos normativos são de fato interpretados de diferentes e variados modos (em boa parte dos casos, de modos divergentes) Cf. Guastini (2001, p. 43).

8 A famosa tese da moldura não representa de forma alguma uma teoria hermenêutica para o direito. Mas não parece ser mesmo esse o objetivo de Kelsen na Teoria pura do direito, pois que afirma expressamente que "não há qualquer método - capaz de ser classificado como de direito positivo - segundo o qual, das várias significações verbais de uma norma, apenas uma possa ser destacada como correta”. (KELSEN, 1987, p. 367)
} 
O problema propriamente jurídico-epistemológico, em sentido técnico e também ético, refere-se à necessidade de vinculação da decisão judicial à norma jurídica previamente estabelecida. É o problema da discricionariedade judicial em oposição à arbitrariedade das decisões injustificadas (o que Ricoeur chama de "papel tapa-buraco" do juiz). O postulado teórico - comumente vislumbrado na hermenêutica jurídica de Dworkin - da necessidade de se alcançar em todo e qualquer caso jurídico uma resposta não pode escapar à indagação sobre a irracionalidade da arbitrariedade no caso em que há inversão de papéis e o juiz se transforma em legislador. (RICOEUR, 2008, p. 156)

A saída para o problema da arbitrariedade iminente da decisão proposta por Dworkin estaria na hermenêutica literária (DWORKIN, 2001, p. 221) tomada como modelo de racionalidade, em especial, na estética do modelo do texto narrativo. A interpretação de obras literárias, segundo essa tese, não teria o objetivo de descobrir a melhor interpretação de uma obra, mas deveria fazer com que a obra fosse interpretada como a melhor obra de arte possível a partir daquele texto. Aqui, inspirado por essa tese de Dworkin, Ricoeur recorre novamente a mais uma analogia (metafórica, eu diria), dessa vez entre direito e crítica literária. Se na crítica literária há uma oposição entre "sentido imanente ao texto" e "intenção do autor", na teoria do direito pode-se referir a disjunção entre "sentido da lei" e "instância da decisão". A interpretação, assim, deveria ser concebida como reconstrução do sentido do texto. (RICOEUR, 2008, p. 157)

A concepção dialética mencionada acima aparece mais uma vez, mas agora como modo hermenêutico de abordagem do problema interpretativo. A propósito, o recurso à dialética não é algo recente no pensamento de Ricoeur e tampouco restrito à compreensão do fenômeno jurídico. A dialética entre evento e sentido contextualizada no processo de estruturação da linguagem como discurso indica que o que deve ser compreendido hermeneuticamente não é o próprio evento (isto é o discurso constituído), mas a sua significação. (RICOEUR, 1977, p. 46-47)

Ricoeur fala nas relações de interpretação recíproca entre parte e todo de uma obra, um velho problema filosófico (e dialético) que reaparece no âmbito da investigação hermenêutica. De fato, o recurso à dialética 
propicia a superação da dicotomia entre demonstrabilidade e arbitrariedade como alternativas que se excluem mutuamente. Dworkin sem dúvida se opõe radicalmente à tese da demonstrabilidade típica de algumas das teorias juspositivistas - especialmente as legalistas - em que a decisão é um caso de inferência lógica e, portanto, cogente e necessária. No entanto, a crítica de Ricoeur a Dworkin se refere ao exagero na oposição à demonstrabilidade que culmina no desprezo de uma teoria da argumentação.

Vale salientar que as teorias da argumentação contemporâneas pouco têm da antiga teoria da argumentação, ou seja, da retórica. O ideal de racionalidade almejado pelos teóricos contemporâneos nunca esteve presente na retórica clássica. Por mais que retórica e dialética se aproximassem no que refere as suas estruturas formais, ainda assim se está diante de diferentes artes, com âmbitos de aplicação distintos. A dialética em Aristóteles vale-se da argumentação, mas com o objetivo de demonstração silogística da verdade 9 . Na retórica, como mencionado, a verossimilhança basta aos fins do discurso. O que se faz atualmente em teoria da argumentação, com o estabelecimento de procedimentos e formalização dos argumentos, é justamente um incremento da dialética e não uma continuação da retórica.

A argumentação jurídica é atualmente considerada um caso especial da discussão prática (ALEXY, 1997, p. 34, 38, 205-212). Para Ricoeur, isso representa uma aproximação dos conceitos de fundamentação e justificação em relação à noção de interpretação. O plano do discurso prático normativo se caracteriza na medida em que "prático" representa o campo das interações humanas e "normativo", a pretensão à correção - Richtigkeit em alemão, ou rectitude em espanhol, ou ainda, correctness em inglês (RICOEUR, 2008, p. 161). Por outro lado, o conceito de discurso denota o formalismo da argumentação. Em Habermas a ideia de "correção" corresponde à pretensão criada pela inteligibilidade (comunicabilidade universalizável) de um bom argumento que idealmente seja não só entendido, considerado plausível, mas também aceitável por todas as partes envolvidas (tese do acordo potencial). Tudo isso com o objetivo

9 Sobre as relações entre dialética e verdade na filosofia antiga, ver Gadamer (2007, p. 11-49). 
de se atingir um consenso universal em uma comunidade sem limites nem coerções. (HABERMAS, 2004, p. 107-108, 118-121)

Assim, uma pragmática universal do discurso se define por três elementos: primeiramente, pelo seu tom normativo, em segundo lugar pela oposição à argumentação estratégica e, por fim, na contraposição entre sucesso e correção. O caráter contrafactual da noção de correção é responsável pela legitimação de seu estatuto transcendental, isto é, de uma tarefa sem fim (HABERMAS, 1996, p. 9-16). Segundo Ricoeur, "[...] a universalização possível de argumento é aquilo que constitui a sua correção". No plano da comunicabilidade, pressupõe-se a compreensão compartilhada e a discutibilidade - condições de aceitabilidade a que se submete uma decisão tomada num âmbito discursivo limitado ("auditório universal” de Perelman). Segundo Ricoeur, na verdade, há uma série de auditórios envolvidos no discurso e preocupados de modos concretamente diferentes com a pretensão de correção. (RICOEUR, 2008, p. 162-163)

Já na teoria da argumentação jurídica, Alexy introduz a noção de interpretação com as regras que governam a interpretação das necessidades próprias ou alheias como generalizáveis ou não. Neste momento surge uma oposição entre discurso prático geral e discurso jurídico (ALEXY, 1997, p. 311-312). As condições do discurso jurídico são peculiares em relação ao discurso geral. Ricoeur toma como paradigma do discurso jurídico o que se desenvolve na instância judiciária, isto é, no âmbito dos tribunais, enquanto Alexy sustenta que a pretensão à correção no discurso jurídico é a mesma que se impõe como horizonte no discurso prático geral (normativo). Em certos sistemas jurídicos essa pretensão se concretiza na obrigação de motivar as decisões.

É com relação à exigência de correção, portanto, que Alexy desenvolve a dicotomia entre justificação interna e justificação externa (ALEXY, 1997, p. 214-222). A justificação interna se refere à coerência lógica entre premissas e conclusão (argumentação como inferência). A coerência interna, portanto, está ligada à dedução, que no direito é representada pela subsunção da norma aos fatos. No entanto, Ricoeur observa que o silogismo jurídico que tem como premissas a norma e o fato na verdade repre- 
sentam um caso de "ajuste" entre norma e fato: o fato se ajusta à norma, assim como a norma deve se ajustar também ao fato ${ }^{10}$.

A aplicação de uma regra é, na verdade, uma operação muito complexa na qual a interpretação dos fatos e a interpretação da norma se condicionam reciprocamente, antes de chegarem à qualificação por meio da qual se diz que determinado comportamento presumidamente delituoso incide sob determinada norma que se diz ter sido transgredida. (RICOEUR, 2008, p. 168)

A subsunção, pois, é problemática na medida em que afirmar que a premissa menor (o fato) é um caso da premissa maior (a norma) parte já da presunção de que o silogismo jurídico vale. A teoria da argumentação não rompe com a noção silogística, mas tenta superá-la na medida em que propõe o encadeamento de argumentos que decompõem o silogismo. Ricoeur questiona, contudo, se é possível, na subsunção, mesmo por graus decompostos, dispensar uma interpretação conjunta de normas e fatos por ajuste recíproco. Ele responde dizendo que

[...] pessoalmente, eu diria que a interpretação se tornou o órganon da inferência. [...] Nesse sentido, a interpretação não é exterior à argumentação: constitui o seu órganon. Mesmo a idéia de casos semelhantes assenta na interpretação de uma analogia; é assim que se deve sempre interpretar ao mesmo tempo a norma como aquilo que cobre, e o caso, como aquilo que é coberto, para que funcione o silogismo jurídico que, doravante, não difere em nada do silogismo prático geral. (RICOEUR, 2008, p. 168)

\footnotetext{
${ }_{10}$ A indutividade do raciocínio jurídico põe em relevo esse caráter adaptativo das regras jurídicas. A cada nova decisão, isto é, ao passo em que cada novo caso é decidido, surge a necessidade de reclassificação das normas aplicadas. "As normas se modificam ao serem aplicadas" (HUNTER, 1998, p. 374). A norma, como conceito ideal, portanto, não se mantém incólume aos fatos. Na medida em que uma norma é aplicada a diversos fatos concretos, o seu próprio significado se modifica. É o que se consolida em um contínuo processo de inferência indutiva. O silogismo, portanto, não se aplicaria ao raciocínio jurídico, dado que a premissa maior é moldada pela premissa menor; pois o fato determina a norma.
} 
A teoria da argumentação jurídica procura não separar descoberta e justificação. Assim, Ricoeur conclui que a interpretação está incorporada na própria justificação interna. Já no plano da justificação externa (a justificação das premissas) o entrecruzamento de argumentação e interpretação parece indiscutível. Assim como Dworkin, ele entende que os fatos de um caso concreto "[...] não são fatos brutos, mas estão impregnados de sentidos, portanto interpretados". E reafirma que "a imbricação entre a argumentação e a interpretação, no plano judiciário, é realmente simétrica à imbricação entre explicação e compreensão no plano das ciências do discurso e do texto". Por fim, conclui com a extensão do aforismo "explicar mais para compreender melhor" à dicotomia entre argumentação e interpretação que fica subentendida no texto como "argumentar mais para interpretar melhor".

\section{O Caráter Metafórico da Linguagem dos Modelos Teóricos do Direito}

Toda essa discussão teórica decorrente do confronto entre teorias da argumentação jurídica de um lado e, de outro, teorias interpretativas do direito dentro de um mesmo contexto pós-positivista serve como exemplo de um debate que não se resolve no mesmo plano teórico. São diferentes modelos de racionalidade para a produção do direito. Cada modelo com sua narrativa própria e seu vocabulário particular. Daí a inquietação de Paul Ricoeur diante do antagonismo entre as teorias e de sua mútua exclusão. São teorias que surgem em um contexto aparentemente idêntico, mas que apresentam propostas completamente diferentes de representação (ou construção?) teórica da razão jurídica. Cabe investigar se esses modelos realmente são capazes de descrever a realidade do direito ou se não passam de pura mímica, fábula ou alegoria. Ou ainda, em uma posição intermediária, se os modelos da teoria do direito são na verdade metáforas epistêmicas capazes de produção de conhecimento ao mesmo tempo em que representam e criam a própria noção de direito.

A teoria dos modelos científicos, especialmente no âmbito jurídico, pode ser encarada também como uma retórica (no sentido de retórica ana- 
lítica) dos modelos se os modelos forem entendidos como metáforas. Há, por trás de toda formulação teórica do direito, uma ideia de modelo que parte de um objeto particular - de uma figura ou imagem que pode ser observada na experiência e percebida por meio dos estímulos capturados pelos sentidos, como, por exemplo, um comando dado por uma autoridade a um subordinado, ou o conflito entre prescrições antagônicas que não podem ser aplicadas contemporaneamente. No processo de construção do modelo teórico, esse objeto particular é selecionado entre vários outros candidatos que serão posteriormente compreendidos a partir daquele que foi escolhido como seu representante. Dessa forma, na teoria do direito, como no exemplo da teoria da norma jurídica, o modelo proporciona a esperança de generalizar resultados ao assumir que, a partir de um enunciado prescritivo particular, é possível falar genericamente - teoricamente - no conceito de norma; ou, levando em consideração um conjunto de prescrições entendidas como normas positivas de um espaço histórica e geopoliticamente determinado, chegar ao conceito de ordenamento jurídico. Essas generalizações subentendem a ideia de um modelo geral que será empregado, agora não mais de baixo para cima, ou seja, indutivamente do concreto para o abstrato, mas de cima para baixo, dedutivamente do geral para o particular. Assim, por exemplo, o modelo de norma servirá para explicar teoricamente uma prescrição particular, ou o modelo de ordenamento será empregado para compreender o direito empírico de um determinado Estado e garantir seu caráter sistêmico, unitário, hierárquico e coerente eliminando suas possíveis contradições ou antinomias.

Algo importante que deve ser considerado é a possibilidade mútua de compreender o modelo como o representado ou como a representação - fenômeno presente não só na linguagem natural como também na científica. Isto é, tanto pode-se entender o representado como sendo o modelo, como, por exemplo, uma pessoa que se deixa fotografar, quanto pode-se dizer que a fotografia (a representação) é que é o modelo da pessoa representada. No primeiro caso, quando se entende que o modelo é o representado, seria o mesmo que afirmar que o imitado é o modelo e a imitação apenas sua representação, ou ainda, para adotar o mesmo exemplo, o fotografado é o modelo enquanto a fotografia é a sua representação. No segundo caso, quando a representação, e não mais o representado, é 
o modelo, há uma inversão, de modo que o modelo passaria a ser a imitação enquanto o representado seria o imitado, ou, em outro exemplo, a pintura figuraria como modelo enquanto o pintado seria o representado. $\mathrm{Na}$ ciência, um caso típico de modelo como representado é o da teoria dos modelos da lógica, especialmente no que se denomina modelo matemático, de forma que o modelo, nessa acepção, é uma interpretação ou projeção que apresenta os correlatos formais da realidade explicada pela teoria. Já especificamente nas ciências sociais, comumente os modelos atuam como uma espécie de simplificação quantitativa da realidade representada. (PALMA, 2004, p. 45-46)

Há, portanto, sempre, no modelo, uma relação entre representado e representação. No direito poder-se-ia pensar nos seguintes exemplos: a relação entre o direito positivo de certo Estado e a ideia de ordenamento jurídico como sendo respectivamente o representado e a sua representação. Ou ainda, um debate judiciário concreto como o representado e a formalização das argumentações como sua representação. E, por que não, a relação entre o produto da interpretação de um texto normativo empírico e o conjunto de normas que se apresentam como critérios formais para a solução de conflitos judiciais.

No âmbito das teorias hermenêuticas contemporâneas passou-se a diferenciar texto normativo de norma jurídica, na medida em que o texto ainda não é a norma e tampouco poderia a norma ser reduzida a seu texto. $\mathrm{O}$ texto seria assim anterior à norma, pois ela seria o resultado do processo de interpretação (ou concretização) de um texto ou de um conjunto de textos específicos, somados a elementos externos ao próprio texto (no que se costuma chamar de contexto, como, por exemplo, os dados concretos da realidade, valores socialmente compartilhados, expectativas de consenso bem-sucedidas, além de outros elementos também textuais que formam o que se chama de co-texto). Assim, se tomar essa tese como certa, diante da relação entre texto e norma, poder-se-ia afirmar que o texto é o representado e a norma a sua representação, pois o texto é anterior à norma. Mas não seria possível também afirmar o contrário: a norma como sendo o representado e o texto sua representação? Nesse caso a norma seria logicamente - mesmo que não cronologicamente - anterior ao tex- 
to. Mas o que deve figurar aqui no exemplo como modelo: a norma ou o texto? Se a norma é o representado, ela determinaria a sua posterior representação textual. Mas se é o texto o representado, a norma é que seria a sua representação e, portanto, pelo texto previamente determinada.

Dessa forma, se pensar o texto como a representação da norma, isso levaria a entender a norma como algo prévio ao processo de interpretação, isto é, uma ideia ou sentido que deverá ser expressado por um texto. Mas, se ao contrário, pensar a norma como a representação do texto, este ser-lhe-ia anterior, determinando a necessidade de sua interpretação segundo o modelo normativo lógico-sintático adotado pela teoria jurídico-dogmática. O problema pode ser ainda elevado à segunda potência se for possível considerar que tanto o representado quanto a representação podem figurar como modelo. Mas e com relação à aproximação entre modelo e metáfora? Se a norma é o modelo do texto, esta interação semântica entre norma e texto poderia ser literal ou deveria ser necessariamente metafórica? E se, ao contrário, o texto fosse o modelo da norma, a resposta seria diferente? Quando se pergunta se a relação entre representado e representação deve ser necessariamente metafórica, isso se deve ao fato de que essa relação não se dá diretamente, mas pressupõe um terceiro elemento: a criatividade (PALMA, 2004, p. 47) que produz o enlace entre as duas realidades.

No campo do estudo das figuras de linguagem, as teorias se dividem, com relação ao valor que as metáforas têm de transmitir informações sobre a realidade, em duas perspectivas distintas, inclusive no que se refere à teoria jurídica (SARRA, 2006). De um lado, existem aquelas que negam qualquer valor informativo e consideram a metáfora como substitutiva da linguagem explanatória por meio da evocação de imagens ou sentimentos. De outro lado, contrariamente a essa posição, há os que defendem que é possível estabelecer uma teoria que admita a função semântica da metáfora. Em geral, os que pertencem à primeira corrente de pensamento são aqueles que relegam a metáfora ao plano da psicologia, em que as imagens e sentimentos predominam. Ricoeur, ao contrário, se inclui entre os que admitem uma semântica da metáfora, mas que para isso seria preciso tratar o que aparentemente é meramente psicológico, isto é, relativo à imaginação e ao sentimento, como fator constitutivo des- 
sa função semântica. É assim que se pode falar em um "papel semântico da imaginação" relativo à metáfora e ao estabelecimento de um sentido metafórico próprio. A imaginação está relacionada a uma função pictórica do sentido metafórico, algo que está na própria expressão "figura de linguagem" cunhada pela tradição retórica. Pois as figuras dão visibilidade ao discurso, fazendo-o "aparecer". (RICOEUR, 1978, p. 151-152)

É importante perceber que ao falar sobre metáforas, os teóricos parecem obrigados a criar novas metáforas. A própria palavra "metáfora" indica ela mesma uma metáfora de deslocamento ou transferência do sentido. A ideia de movimento está presente, portanto, na própria ideia de metáfora. Movimento que indica passagem de um lugar para outro. $\mathrm{O}$ movimento é passagem, e passagem é tradução. A constituição de sentido metafórico, portanto, está ligada à noção de tradução. Em alemão a noção de movimento ou deslocamento da ação de traduzir é mais ostensiva. Traduzir, übersetzen, é a junção da preposição "sobre" (über) com o verbo setzen, cujo significado gira em torno do movimento de "pôr" algo em algum lugar. Metáfora, do verbo grego meta-phéro ou meta-phoréo, entendida como tradução, apela, assim como em alemão, para a noção de movimento, como "levar para outro lugar", "transferir" (DE MAN, 1978, p. 15). Na construção de modelos e na relação entre representado e representação, assim como na interpretação de metáforas, existe também versão ou tradução de uma linguagem em outra.

Por outro lado, o tecnicismo e o objetivismo da linguagem científica parecem ter sido tomados como estalão da perfeição para as outras formas de discurso, dentre as quais, o discurso jurídico. Entretanto, a linguagem da ciência, senão a própria ciência, pode ser entendida como mera forma de controle e predição. A ciência não é mais que um procedimento amplamente aceito e compartilhado, sendo, desse modo, capaz de fixar crenças (RORTY, 1997, p. 220) como a construção de um mundo por meio de um modelo depende da objetivação do modelo quando este é apresentado como uma teoria científica aceitável. (ARBIB; HESSE, 2008, p. 161)

Enquanto a ciência procura, em tese, descrever um mundo que é, que existe, as metáforas permitem criar novos mundos - mundos inauditos. Ou seja, as metáforas não apenas "representam”, mas elas próprias 
constituem eventos desse mundo inaudito. O ponto de vista que admite a produção um sentido metafórico próprio na linguagem figurada entende que no momento em que uma metáfora é criada, é como se um novo mundo simbólico surgisse (DAVIDSON, 2008, p. 473). Mesmo considerando que as metáforas, para oferecerem um significado, dependem do prévio conhecimento de seu emprego literal na linguagem - pois que de outra forma, não haveria metáfora, apenas sons inauditos que nada representam - entender a literalidade é insuficiente para a compreensão do significado metafórico.

Para que um texto torne-se a descrição de um conceito jurídico é preciso que se torne um padrão para crença nesse conceito. É nesse sentido que Ottmar Ballweg e Katharina (Sobota) von Schlieffen falam em regularidades, inclusive no direito, como "formações cibernéticas dinâmicas" ou "padrões construídos por um observador dentro de um sistema" (SOBOTA, 1995, p. 254). As regularidades, ao mesmo tempo em que são criador, são criatura. As metáforas, por sua vez, arriscam-se diante de regularidades num continuo jogo de aproximação e distanciamento.

Não se trata, com efeito, de uma questão de ontologia, das coisas como elas são, mas de autoridade, de como se decreta que as coisas são. E essa autoridade não pode ser investida de nenhum caráter autorizado, pois o uso livre da linguagem comum é conduzido, como faz a criança, pela figuração irrefreada, que zomba da mais autoritária academia. Não temos meio de definir, de policiar as fronteiras que separam o nome de uma entidade do nome de outra; os tropos não são apenas viajantes - tendem também a ser contrabandistas e, provavelmente, contrabandistas de bens roubados. O que torna as coisas ainda piores é que não há como descobrir se fazem isso com intenção criminosa ou não. (DE MAN, 1992, p. 24)

O estabelecimento de modelos teóricos para o desempenho da atividade dogmática do jurista surge muitas vezes, não como descrição do direito, mas como reflexo da ideologia e da visão de mundo do jurista em determinado contexto histórico do qual ele não pode sair. Mais do que "saber" o que o direito é, as teorias desenvolvem narrativas que apresentam o direito como se "quer" que ele seja. Isso significa dizer que o pro- 
pósito de recriação da realidade estaria mais presente na atitude dos teóricos do direito do que um comportamento simplesmente descritivo.

Já o modelo das teorias se aproxima da metáfora na analogia que se faz entre poética e ciência. Como afirma Ricoeur, "[...] a metáfora é para a linguagem poética o que o modelo é para a linguagem científica" (RICOEUR, 2005, p. 366). Para Max Black (1978, p. 181), a habilidade de criar e entender metáforas, assim como a capacidade de contar e de rir de uma piada é algo absolutamente natural nos seres humanos, algo que a criança desenvolve espontaneamente ao aprender a falar, sem que seja necessariamente dotada de talento poético ou literário. As sobras epistemológicas que se confirmam empírica ou experimentalmente na ciência pertencem ao domínio da "imaginação científica", ou do "engenho e arte". O modelo na teoria do direito, como categoria formal, visa a atender necessidades pragmáticas da retórica jurídica (CASTRO JR., 2009, p. 2526), ou mesmo a preencher, metaforicamente, o "vazio epistemológico" de sua ciência, algo relacionado à capacidade de intuir o mundo, própria do ser humano. (CASTRO JR., 2009, p. 23)

A teoria dos modelos desenvolvida por Max Black e por Mary Hesse percebe que, na linguagem científica, o modelo atua como um instrumento heurístico de interpretação ou redescrição e se apresenta em três diferentes níveis. Do mais baixo para o mais alto eles se dividem em modelos de escala, modelos análogos e modelos teóricos. Os modelos de escala funcionam a partir de uma relação assimétrica entre a coisa e o modelo. São simulacros de objetos materiais reais ou imaginários que mantêm as relações de proporção do original. O exemplo mais significativo é a maquete que reduz um objeto muito grande e, portanto, difícil de enxergar em sua totalidade, a uma sua miniatura. O contrário também é possível, como por exemplo, na representação de um átomo, ou de uma cadeia de DNA, cujo objetivo é mostrar como a coisa funciona ou que aspecto ela tem, para em seguida extrair as leis que determinam a sua atuação. É importante ressaltar que as maquetes não precisam manter - e geralmente não mantêm - as propriedades do objeto representado, pois a miniatura de uma represa, por exemplo, pode ser fabricada com um material completamente diferente da represa original que se pretende construir ou que já foi construída. O objetivo da modelagem pode ser somente a re- 
presentação de um dos aspectos do objeto representado. Mas pode ser que se dê o contrário e a proporção não interesse tanto, mas apenas o grau de resistência do material utilizado. Assim, todo modelo de escala enfatizará alguns traços do original, desprezando outros não relevantes ou indiferentes para os propósitos práticos da produção do próprio modelo (PALMA, 2004, p. 48). O modelo de escala, portanto, é empregado na adaptação ao nível da compreensão humana de coisas inicialmente inapreensíveis ao nosso aparato cognitivo em virtude de seu macro ou micro dimensionamento. Mas entre o modelo e o modelado existirá sempre uma relação assimétrica que não permitirá a conversão de um em outro. $\mathrm{O}$ modelo $\mathrm{A}$ de um objeto modelado B (por exemplo, a maquete de uma ponte) não admite a inversão de posições, pois o objeto modelado B não poderá se transformar no modelo A, ou, para usar o nosso exemplo, a ponte original não pode se transformar em modelo para a sua maquete. Os modelos de escala, na verdade, não têm um fím em si mesmo. São sempre substitutos instrumentais na medida em que representam um meio para a compreensão de algo à primeira vista incompreensível. De qualquer maneira, somente alguns aspectos do objeto original poderão ser representados no modelo, o que determina que entre modelo e modelado haverá uma identificação apenas parcial. Obviamente a falta de identidade total levará à necessidade de regras de interpretação do modelo para que o original seja compreendido adequadamente.

O modelo analógico, por sua vez, desempenha uma representação estrutural por meio da mudança do meio (medium) como uma tradução de um sistema de relações para outro. $\mathrm{O}$ isomorfismo entre modelo e coisa representada se dá pela semelhança entre estruturas, e não pela aparência. É o que acontece com a representação do átomo por meio do sistema solar tomado como modelo de estrutura para o movimento das partículas subatômicas. Pode-se dizer que os modelos, especialmente o modelo analógico, desempenham uma função psicológica importante na medida em que servem a funções heurísticas e didáticas de compreensão científica da realidade. Os modelos analógicos servem para simplificar as inferências de estruturas mais complexas. É esse o tipo de modelo que mais se aproxima da noção de "metáfora epistêmica". (PALMA, 2004, p. 50) 
Os modelos teóricos, por fim, pertencem ao nível mais alto da teoria ao introduzirem uma linguagem nova, porém descritiva do original (RICOEUR, 2005, p. 366-368). Modelos desse tipo são mais pretensiosos no que se refere ao seu poder explicativo ou comprobatório. O modelo teórico da ciência procura ser a representação realista do fenômeno além de servir como instrumento de predição. O mais importante é que sempre há um compromisso ontológico que pode variar de um grau mínimo de pressuposições acerca da realidade até o grau máximo que determina que o modelo seja uma verdadeira cópia ou imagem concreta dos fenômenos.

No nível teórico, portanto, o funcionamento do modelo, ao introduzir esse novo idioma (ou mundo simbólico), se aproxima ao da metáfora, pois a explicação teorética pode ser comparada à atividade de redescrição metafórica. Na ciência, o recurso à redescrição metafórica é um sintoma da impossibilidade de se obter uma relação puramente lógica ou dedutiva entre a explicação e o que é explicado. A racionalidade consiste precisamente na adaptação ininterrupta de nossa linguagem a um mundo em contínua expansão, e a metáfora é um dos principais meios pelos quais isto se efetua. (RICOEUR, 2005, p. 370)

É importante reafirmar que somente os traços pertinentes são revelados no modelo de acordo com o nível de abstração a que pertença. Do nível imagético da cópia ampliada ou reduzida, passa-se pelo isomorfismo estrutural que despreza o aparente e ressalta o que há por trás da imagem, para chegar ao nível mais alto de abstração do modelo teórico que procura descrever a coisa com um novo mundo, ou uma nova dimensão, do qual não faz parte a própria coisa. De toda sorte, o caráter positivo do uso dos modelos pode ser vislumbrado na aproximação da ideia de modelo em relação à noção de metáfora. A capacidade de expansão e de readequação do modelo é semelhante à capacidade de expansão semântica das metáforas. A expansão ou transformação semântica das metáforas permite a introdução de novos significados em um idioma, da mesma forma que a capacidade de expandir e transformar uma teoria depende da interpretação que se dê ao modelo.

Claro, quanto maior o grau de formalização de uma teoria, menor o seu "sabor metafórico" (CASTRO JR., 2009, p. 68). Mas isso se a lingua- 
gem formalizada não for entendida ela própria como uma interpretação metafórica do observado. Não é possível dizer se os juristas teóricos que se preocupam em demonstrar seus argumentos não só por meio de conceitos linguísticos, mas também por meio de enunciados formais expressados simbolicamente, fazem-no por uma necessidade epistemológica assim como na matemática - ou se são apenas estratégias de apresentação que causam impacto diante da ignorância ou do pouco conhecimento de boa parte de seus leitores. O que se pode intuir é que para os que nada sabem de lógica, a linguagem formalizada do cálculo sentencial ou do cálculo de predicados, causa espanto; para os que decifraram essa linguagem e têm alguma intimidade com os operadores, categoremas ou sincategoremas da lógica, os enunciados não passam de pura redundância (o que não é um problema para a lógica, vista ser feita de tautologias) ${ }^{11}$.

No entanto, a univocidade que se espera na linguagem teórica depende certamente de sua formalização. A linguagem natural, diante dos problemas causados pela ambiguidade de seus conceitos, pela vagueza de suas expressões e pela porosidade a que está submetida diante de seu caráter historicamente determinado tem pouca ou nenhuma relevância epistemológica. Daí a necessidade de se recorrer a uma nova linguagem específica e unívoca, como a linguagem da lógica formal. A questão é que, se a linguagem natural diz muito, mais do que devia, causando uma série de problemas interpretativos e comunicacionais de falsa compreensão, uma linguagem formalizada, unívoca, por ser tautológica, autorreferente, por si só, nada diz, não acrescenta dado algum sobre a realidade (HEGENBERG, 1977, p. 9). Sua univocidade resulta do princípio da identidade em que $p$ é exatamente igual a $p$ e somente a $p$. O que interessa à lógica é a sua coerência do ponto de vista sintático, e não semântico.

Claro que não se pode fazer ciência assim, pelo menos no sentido de uma ciência empírica como é em parte a teoria do direito. Ou melhor, não se pode produzir conhecimento algum sem uma linguagem que capture a essência das coisas e as traduza em uma nova linguagem. A uni-

\footnotetext{
11 No caso de autores como Neil MacCormick ou Robert Alexy, há certa consciência de que a linguagem formal empregada é um misto de esforço epistemológico com fantasia literária. Cf. Maccormick (1997, p. 19-25).
} 
vocidade que se pretende na ciência é coerente com a noção de "verdade como correspondência". Mas o sentido literal que se almeja no linguajar teórico depende da crença de que a teoria representa um "decalque do mundo" em que a teoria da verdade como correspondência indica a existência prévia de um mundo dual. (CASTRO JR., 2009, p. 77)

A univocidade e o significado literal na teoria dogmática do direito são, portanto, operacionalmente fundamentais, mas não lhe pertencem. Aliás, nada do que pode ser chamado literalmente de científico na ciência do direito é originalmente seu. O que não é roubado é emprestado, mesmo que compulsoriamente. Assim, se os modelos científicos como um todo já podem ser caracterizados como metáforas, no âmbito do direito, falar em ciência e recorrer a modelos científicos é uma dupla metáfora, na medida em que a expressão "ciência jurídica" não poderá nunca ser tomada literalmente, tampouco vir desacompanhada de aspas. Tomar os modelos da "ciência do direito" como metáforas é essencial ao desenvolvimento criativo e adaptativo do próprio direito da mesma forma que permite compreender a sua mutabilidade intrínseca.

\section{Referências}

ADEODATO, João Maurício. A retórica constitucional. Sobre tolerância, direitos humanos e outros fundamentos éticos do direito positivo. São Paulo: Saraiva, 2009.

. Ética e retórica. Para uma teoria da dogmática jurídica. São Paulo: Saraiva, 2009.

ALEXY, Robert. Teoria de la argumentación jurídica. La teoria del discurso racional como teoria de la fundamentación jurídica. Tradução de M. Atienza e I. Espejo. Madrid: Centro de Estudios Consitucionales, 1997.

ARBIB, Michael A.; HESSE, Mary B. The construction of reality. New York: Cambridge University Press, 2008. 
BALLWEG, Ottmar. Analytical rhetoric, semiotic and law. In: KEVELSON, Roberta. Law and semiotics. v. 1. New York: Plenum Press, 1987, p. 25-33.

. Analytische Rhetorik als juristische Grundlagenforschung. In: ALEXY, R.; DREIER, R.; NEUMANN, U. (Hrsg.) Archiv für Rechtsund Sozialphilosophie. Beiheft 44. Stuttgart: Franz Steiner Verlag, 1991a, pp. 45-54.

. Phronetik, Semiotik und Rhetorik. In: BALLWEG, Ottmar; SEIBERT, Thomas-Michael (Hrsg.). Rhetorische Rechtstheorie. Freiburg/München: Verlag Karl Alber, 1982.

. Retórica analítica e direito. Tradução de João Maurício Adeodato. Revista Brasileira de Filosofia, v. XXXIX, fasc. 163, julhoagosto-setembro. São Paulo, p. 175-184, 1991 b.

BIX, Brian. Law, language and legal determinacy. Oxford: Clarendon Press, 2003.

BLACK, Max. How metaphors work: a reply do Donald Davidson. In: SACKS, Sheldon (Ed.). On metaphor. Chicago and London: University of Chicago Press, 1978, p. 181-192.

CASTRO Jr., Torquato. A pragmática das nulidades e a teoria do ato jurídico inexistente. Reflexões sobre metáforas e paradoxos da dogmática privatista. São Paulo: Noeses, 2009.

DAVIDSON, Donald. What metaphors mean. In: MARTINICH, A. P. (Ed.) The philosophy of language. New York: Oxford University Press, p. 473-484, 2008.

DE MAN, Paul. The epistemology of metaphor. In: SACKS, Sheldon (Ed.). On metaphor. Chicago and London: University of Chicago Press, 1978, p. 11-28.

DEL FRATE, Paolo Alvazzi. L'interpretazione autentica nel XVIII secolo. Divieto di interpretatio e "riferimento al legislatore" nell'illuminismo giuridico. Torino: Giappichelli, 2000. 
DESCARTES, René. O discurso do método. Para bem dirigir a própria razão e buscar a verdade nas ciências. Trad. P. Nassetti. São Paulo:

Martin Claret, 2004.

DWORKIN, Ronald. Uma questão de princípio. Trad. L. C. Borges. São Paulo: Martins Fontes, 2001.

GADAMER, Hans-Georg. La dialéctica de Hegel. Trad. M. Garrido. Madrid: Cátedra, 2007.

GUASTINI, Riccardo. Realismo e antirealismo nella teoria dell'interpretazione. Ragion pratica. n. 17. Bologna: Il Mulino, 2001, p. 43-52.

HABERMAS, Jürgen. Racionalidade e comunicação. Trad. P. Rodrigues. Lisboa: Edições 70, 1996.

. Verdade e justificação. Ensaios filosóficos. Trad. M. C. Mota. São Paulo: Loyola, 2004.

HART, Herbert L. A. Il concetto di diritto. Trad. M. Cattaneo. Torino: Einaudi, 2002.

HEGENBERG, Leônidas. Lógica. O cálculo sentencial. São Paulo: EPU, 1977.

HUNTER, Dan. No wilderness of single instances: inductive inference in law. Journal of legal education, USA, v. 48, n. 3, september, 1998, p. 365-401.

JUST, Gustavo. Guinada interpretativa. In: BARRETO, Vicente de Paulo. Dicionário de filosofia do direito. Rio de Janeiro: Renovar, 2006, p. 394-398.

KELSEN, Hans. Teoria pura do direito. Trad. J. B. Machado. São Paulo: Martins Fontes, 1987.

MACCORMICK, Neil. Legal reasoning and legal theory. Oxford: Clarendon Press, 1997. 
PALMA, Héctor A. Metáforas en la evolución de las ciencias. Buenos Aires: Jorge Baudino Ediciones, 2004.

RICOEUR, Paul. A metáfora viva. Trad. D. Macedo. São Paulo: Loyola, 2005.

. Interpretação e ideologias. Trad. e org. H. Japiassu. Rio de Janeiro: Francisco Alves, 1977.

. Interpretação e/ou argumentação. In: RICOEUR, Paul. O justo. v. 1. São Paulo: Martins Fontes, 2008, p. 153-173.

. The metaphorical process as cognition, imagination, and

feeling. In: SACKS, Sheldon (Ed.). On metaphor. Chicago and London: University of Chicago Press, 1978, p. 151-158.

RORTY, Richard. Objetivismo, relativismo e verdade. Trad. M. A. Casanova. Rio de Janeiro: Relume-Dumará, 1997.

SARRA, Claudio. Metafora e diritto. Centro di Ricerche sulla Metodologia Giuridica. [2006]. Disponível em: <http://www.cermeg.it/ category/convegni-e-seminari/attivita-2006>. Acesso em: 10 ago. 2010. SOBOTA, Katharina. Não Mencione a Norma! Trad. J. M. Adeodato. Anuário dos Cursos de Pós-Graduação em Direito, Recife, Universitária, n. 7, p. 251-273, 1995.

VIEHWEG, Theodor. Tópica e filosofia del derecho. Trad. J. M. Seña. Barcelona: Gedisa, 1991.

WAISMANN, Friedrich. Logik, Sprache, Philosophie. Stuttgart: Reclam, 1985.

Pedro Parini é Professor do Centro de Ciências Jurídicas da Universidade Federal da Paraíba, Mestre e Doutor em Teoria e Filosofia do Direito pela Universidade Federal de Pernambuco.E-mail: pparini@gmail.com.

Endereço profissional: Departamento de Direito Privado/Centro de Ciências Jurídicas (CCJ) - Universidade Federal da Paraíba Jardim Cidade Universitária, s/n, Castelo Branco João Pessoa, PB. CEP: 58051-900. 